derived a parameter SOSS (Set of oligostickiness similarity score) from a set of oligostickiness obtained by 12 different probes and used it to calculate the similarity of genomes $(n=33)$ together with the $\mathrm{G}+\mathrm{C}$ content and the codon usage analyses termed COUSS (Codon usage similarity score) to evaluate the similarity of two genomes. We found (i) The host-parasite relationship could be clearly revealed by SOSS values providing distinctively higher values than that of non-related bacteria and phages. (ii) Lysogenic phages showed higher SOSS to their host than nonlysogenic phages. (iii) Lysogenic phages tend to have a similar $\mathrm{G}+\mathrm{C}$ content to that of their host; however, this property is not diagnostic in discriminating or characterizing the phages. (iv) Lysogenic phages tend to score higher COUSS than nonlysogenic phages to their host with a few exceptions. These results indicate that oligostickiness analysis is most significant in revealing host-parasite relationship. Therefore, oligostickiness analysis can be used to discover unknown host-parasite relationships among a diversity of wild viruses, especially offered by the metagenome analysis.

\section{P-301 蛋白質進化のコドン置換モデル}

A Codon-based Model for Evolution of Protein-coding DNA Sequences

Sanzo Miyazawa. (Graduate School of Engineering, Gunma University)

Reliability of phylogenetic analyses strongly depends on models assumed for the substitution processes of nucleotides and amino acids. Here we propose a new codon-based model in which codon replacements with single and multiple base changes occur in the same order of time, and a new evaluation of the selective restraints on amino acid replacements is used. The codon substitution process is modeled as the time-reversible Markov process and the codon mutation rates are assumed to be proportional to the equilibrium codon frequencies. All codon replacements are assumed to be lethal or neutral, and the mean fraction of neutral replacements is approximated by the exponent of a linear combination of two terms, mean increment of contact energies between an amino acid and surrounding amino acids due to an amino acid exchange in a protein structure and volume difference between an amino acid and its replacement. This codon-based model is examined by maximizing its likelihoods to the amino acid substitution matrices, JTT tallied by Jones et al., mtREV estimated for mitochondria- and cpREV for chloroplast-encoded proteins. The maximum likelihoods indicate that the present evaluation of the selective restraints better fit the JTT than both Grantham'sand Miyata's distances. The Akaike information criterion scores indicate the significance of multiple base changes. The estimated values of parameters confirm transition/transversion rate bias and codon usage bias, and reprodnce characteristic features in the temporal changes of the log-odd matrix.

\section{P-302 酵母のタンパク質間相互作用ネットワークにおける進化的拘束と} してのモジュラ一性

Modularity as an evolutionary constraint on the yeast protein interaction networks.

Masataka Kikuchi(1), SoichiOgishima*(1), Hiroshi Tanaka(2).(1: Dept. of Bioinformatics, Medical Research Institute, Tokyo Medical and Dental University; 2: Dept. of Bioinformatics, School of Biomedical Science, Tokyo Medical and Dental University;

Recently, comprehensive data of protein interactions have been accumulating based on large-scale hybridization methods, and makes it possible to understand the structure and the design of cellular networks. Protein interaction networks (PINs) are known to show remarkable global structures with scale-free, and hub proteins are reported to show significantly low evolutionary rates [Fraser (2002) Science]. PINs are also known to show "small-world" properties, in other words "modularity", thus we hypothesized that it should be an evolutionary constraint on PINs. To prove our hypothesis, we examined the Spearman correlation coefficient between clustering coefficients and evolutionary rates $(\mathrm{dN} / \mathrm{dS})$ of the corresponding genes in the yeast PINs [Guldener (2005) NAR], and showed significantly negative correlation between them in the yeast (Spearman corr coef. $=-0.113, \mathrm{P}=1.53 \times 10-7$ ). We also examined the difference in evolutionary rates between party hubs (which interact with most of their partners simultaneously) and date ones (which bind their different partners at different times or locations) [Han (2004) Nature].We found that party hubs exhibit significantly lower evolutionary rate than date ones (Welch $t$ test $\mathrm{P}=6.245 \times 10-6$ ). These results suggest that "modularity" might be an evolutionary constraint in the evolution of yeast PINs.

\section{P-303 ユーグレナ植物のコハク酸脱水素酵素は新規の超分子呼吸鎖複合 体である}

Succinate dehydrogenase in the Euglenozoa is a novel supramolecular respiratory complex

Tatsushi Mogi (1) and Kiyoshi Kita (1)(1: Dept Biomedical Chemistry, Graduate School of Medicine, Univ of Tokyo)

Mitochondrial succinate dehydrogenase (Complex II) is a four-subuni membrane-bound enzyme ( $\sim 130 \mathrm{kDa})$. Flavoprotein SDH1 oxidizes succinate and transfers electron to iron-sulfur subunit SDH2, consisting of the $2 \mathrm{Fe}-2 \mathrm{~S}$ plant ferredoxin $\left(\mathrm{Ip}_{\mathrm{N}}\right.$ ) and the $4 \mathrm{Fe}-4 \mathrm{~S}$ plus $3 \mathrm{Fe}-4 \mathrm{~S}$ bacterial ferredoxin ( $\mathrm{Ip}_{\mathrm{C}}$ ) domain. A a boundary between SDH2 and membrane anchor subunit SDH3 and SDH4, the reduction of ubiquinone takes place. Recently we purified Complex II from the protozoan parasite Trypanosoma cruzi, the causative agent of Chagas disease and found that the Trypanosomatidae Complex II was a 550-kDa dimer and composed of six each of hydrophilic and hydrophobic subunits (1). Notably SDH2 is heterodimeric; $\mathrm{SDH} 2_{\mathrm{N}}$ and $\mathrm{SDH} 2_{\mathrm{C}}$ contain the $\mathrm{I} \mathrm{p}_{\mathrm{N}}$ and $\mathrm{I} \mathrm{p}_{\mathrm{C}}$ domain, respectively Here we examined properties and the structure of Complex II in Euglena gracilis and Astasia longa, the evolutionary cousins in the Euglenozoa. We found that the enzymes were resistant to quinone-related inhibitors, due to divergent SDH3 and SDH4 subunits. The current database suggests that the Euglenida Complex II is an eight-subunit enzyme lacking soluble subunit SDH5 SDH7. Sequence analysis suggests that Euglenozoa-specific subunits have evolved by duplication and degeneration of canonical subunits. If such degenerated duplicons retain the protein network-forming potential; they would be organized as a nove supercomplex. This could be one of mechanisms for overweighting the mitochondrial respiratory complexes.1) J. Morales, T. Mogi, K. Kita (2008) Biochim. Biophys. Acta 1777, S94.

\section{P-304＼cjkstart様々な粒径・元素のナノ粒子プローブセットで標識された標的} DNA の無増幅定量検出法の開発

Use of a nano-particle probe set for quantitative detection of target DNA without amplification: identification through size and element

Hyonchol Kim (1), Hiroynki Takei (1) and Kenji Yasuda (1,2). (1: Kanagawa Academy of Science and Technology; 2: Inst Biomaterial Bioengineering, Tokyo Medical and Dental Univ)

Monitoring functions and variations of expression profiles in a cellular system is a key to understanding the mechanisms of living organisms, especially to identifying those phenotypical characteristics. The DNA microarray technology has been widely used for such a purpose; however, this method is associated with some technical problems. One of them is lack of the quantification capability due to nonlinear sample amplification. The obtained result is an averaged value of many cells and monitoring of the expression profile in a single cell is in general difficult using this method. These problems are in principle caused by the underlying optical detection methodology based on fluorescent dyes; therefore a new detection system should be devised to measure the expression profile in single cell level. We tried to carry out quantitative and highly sensitive detection of expressed biomolecules using nano-particle probes as labels instead of fluorescent dyes. Nano-particles were prepared different metals in various sizes and probe DNAs were immobilized on the particles. Target DNAs were labeled with the nano-particle probes and both kind and amount of the labeled particles were quantitatively measured using a field emission scanning electron microscope (FE-SEM). Sensitivity of our method was tested using custom ordered DNA microarrays and targets in the femto molar concentration range could be detected without any amplification. These results indicated the advantage of the use of nano-particles as labels.

\section{P-305 極低温電子顕微鏡による高分解能像撮影条件の探索}

Which temperature is optimal for high-resolution Cryo-EM ?

Masamichi Ashihara (1), Takayuki Kato (1), Hideyuki Matsunami (2), Tomoko Miyata (1) and Keiichi Namba (1). (1: Graduate School of Frontier Biosciences, Osaka University; 2: Okinawa Institute of Science and Technology)

The principal resolution limitation in electron cryomicroscopy of frozen-hydrated biological material is low contrast and low signal-to-noise-ratio (SNR) that results from the radiation damage to biological specimen by the electron beam. Increase in the electron dose limit that specimens can tolerate would be the simplest way to improve the SNR. It has been demonstrated that cooling the specimen to $4 \mathrm{~K}$ with liquid helium reduces the damage and allows statistically better images to be recorded. In fact an atomic model of the bacterial flagellar filament has been built from images recorded at $4 \mathrm{~K}$. However, 3-D reconstructions with resolutions of 5 $\AA$ or better from images recorded at $\sim 100 \mathrm{~K}$ have recently been reported. We therefore decided to reexamine how much the liquid-helium cooling is advantageous for recording high-resolution data to higher temperatures and determine optimal electron dose at each resolution. We collected electron diffraction data from 2-D crystals of bacteriorhodopsin (bR) at $4 \mathrm{~K}, 50 \mathrm{~K}$ and 80 $\mathrm{K}$, and quantitatively evaluated the radiation damage at each specimen temperature by following the decay in diffraction intensities with dose accumulation. We found that the radiation damage was smallest at $50 \mathrm{~K}$. The ame evaluation with thin 3-D crystals of a flagellin fragment is under way to confirm the result. We also compared 3-D image reconstructions of the Hepatitis $B$ virus core from images collected at different temperatures and accumulated dose to see the temperature effect on image quality.

\section{P-306 原子間力顕微鏡を用いた抗体一抗原相互作用に対する温度の影響 の言十測}

Measurement of influence of temperature on antibody-antigen interaction by AFM

Jun'ichi Wakayama (1), Shigeru Sugiyama (1). (1: Nano-Biotechnology Laboratory, National Food Research Institute)

Molecular recognition such as interaction between receptor and ligand, as well as antigen and antibody, can be characterized by an energy landscape consisting of potentially energetic barriers along a reaction coordinate. Dynamic force spectroscopy (DFS), which consists of measurements of the rupture forces between a molecule of interest and a complementary molecule at different loading rate by use of atomic force microscopy (AFM), is useful tool to investigate the energy landscape of the interaction at the single molecule level. However, in the measurements of rupture force between antibody and antigen, several studies showed that the forces are often obscured by nonspecific interaction. To study exactly the energy landscape of antibody-antigen interaction by means of DFS, one should reduce the nonspecific interaction. Recently, we demonstrated that the use of an experimental solution containing with both a detergent and a 